\title{
USE OF ASPIRATIONAL PUNCTUATION OF TUMORS WITH FINE NEEDLE (FNAB) FOR THE DIAGNOSIS OF DUCTAL CARCINOMA: ANALYSIS OF CYTOPATHOLOGICAL EXAMINATIONS DONE IN BRAZIL BETWEEN JANUARY 2012 TO JANUARY 2014
}

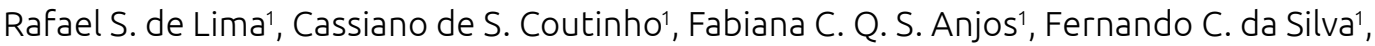
Ildelbrando I. A. C. Sobrinho1, Priscila F. Barbosa', Rayssa de O. Glória1', Vantuir J. D. da Mota1

${ }^{1}$ Centro Universitário de Gurupi - Gurupi (TO), Brazil.

Objective: To analyze the number of exams performed through FNAB, with emphasis on positive results for malignancy, compatible with ductal carcinoma. Method: Cross - sectional study based on data from 6,433 fine - needle aspiration of breast nodules performed between January 2012 and January 2014, registered in Brazil according to the data from SisMama- DataSus. The age range, the states of the country with the highest prevalence and the cytological analysis were evaluated. The nodules were classified as benign, of indeterminate malignancy, suspected for malignancy or malignant. The chi-square test was performed with 5\% significance. Results: Were performed 6433 FNA tests in women aged 50-64 years; being 5560 benign cases (86.43\%); 111 undetermined malignancy (1.73\%); 347 suspect for malignancy (5.39\%); 415 positive for malignancy (6.45\%). Of these, 319 exams (76.87\%) were identified in FNAB as Ductal Carcinoma, being 111 between 50 and 54 years, 108 between 55 and 59 years, and 100 between 60 and 64 years. Statistically, there was an association between the FNA score and the age group, where $10.42 \%$ of the women between 60 and 64 years were diagnosed with malignant nodules ( $\mathrm{p}<0.05)$; in the age group between 55 and 59 years had 132 positive results for malignancy of 1911 exams performed (6.91\%); and in the age group of 50 to 54 years had 143 positive results for malignancy of 3178 tests performed (4.50\%). The states with the highest prevalence of Ductal Carcinoma cases are the states of São Paulo and Minas Gerais, with 75 and 61 cases (23.51\% and 19.12\%), respectively. Conclusion: It was observed that the majority of the cytopathological examinations carried out resulted in benign processes, but a significant number of malignant processes still exist, and of these a predominance of ductal carcinoma was observed, in which the women between 60-64 years present a higher prevalence. Corroborating with the literature, data showed that the prevalence of positive results for malignancy increased with age. According to the Ministry of Health, this neoplasm is observed in about $80-90 \%$ of the cases, and in the present study a rate of approximately $76.87 \%$ was observed. 